MATEC Web of Conferences 13, 02019 (2014)

DOI: $10.1051 /$ matecconf/ 20141302019

(C) Owned by the authors, published by EDP Sciences, 2014

\title{
Comparative Analysis of Two Proposed Models of Connecting rods for Crank-rocker Engines Using Finite Element Method
}

\author{
Salah Eldin Mohammed ${ }^{1, a}$, Masri Baharom ${ }^{2, b}$ and Abdul Rashid Abdul Aziz ${ }^{3}$ \\ 1,2,3 Center for Automotive Research,Department of Mechanical Engineering, UniversitiTeknologi \\ PETRONAS (UTP), Bandar Seri Iskandar, 31750 Tronoh, Perak, Malaysia
}

\begin{abstract}
In this study, static load analysis was performed on two proposed models of connecting rods (conventional and Y-shape con-rod) intended for use in the crank-rocker engine. The analysis was done by modeling the model using CATIA V5 software which was then analyzed using ANSYS Workbench 14.0 software. A static analysis was done to determine the von-misses stresses under tensile and compressive loading conditions. Two cases were studied, firstly, the load was applied at the rocker pin end and fixed at the crank end as a compressive load, and secondly, the load was applied at the same position as a tensile load with both cases under the same constant load. It was found from the analysis that the conventional connecting rod has yielded lower stress values for both cases as compared to the $\mathrm{Y}$-shaped connecting rod. Based on the results, it was concluded that the normal connecting rod is better to be used for the crank-rocker engine.
\end{abstract}

\section{Introduction}

Connecting rods are common machine components which are widely used in numerous machines. The most distinguished ones are used in the internal combustion engines, which transfer energy from the piston to crankshaft and convert the linear, reciprocating motion of a piston to the rotary motion of a crankshaft, and is subjected to complex loading. The demands on the use of suitable connecting rod material have increased; while the connecting rods become smaller and lighter weight. Researchers have proposed many different types of materials and design methods for the fabrication of connecting rods. For example, steel, aluminum and cast iron are common materials used in the construction of connecting rods. The most modern manufacturing methods of the connecting rod are sand casting, wrought forging and powdered metallurgy [1]. In internal combustion engines, the connecting rods are subjected to compressive loads due to gas cylinder pressure and tensile loads due to the inertia force. These forces results in axial and bending stresses. Bending stresses are caused by the thrust and pull on the piston and by the centrifugal force of the rotating crankshaft. Therefore, a connecting rod must be sufficiently strong and rigid [2].

Design and developments have been an important topic in the field of automotive engineering, in order to produce a less expensive component with the optimized weight and proper fatigue strength and other functional requirements. These enhancements result in lighter weight and higher power-to-

${ }^{\mathrm{a}, \mathrm{b}}$ Corresponding author : ${ }^{\mathrm{a}}$ salah_7888@yahoo.com ${ }^{\mathrm{b}}$ masri@petronas.com.my

This is an Open Access article distributed under the terms of the Creative Commons Attribution License 2.0, which permits unrestricted use, distribution, and reproduction in any medium, provided the original work is properly cited. 
weight ratio engines with better fuel efficiency and more powerful engine. Since the connecting rod faces a large number of load cycles during its service life, fatigue strength, stiffness and durability of this component has to be considered in the design process. Prof. N.P. Doshi et al. [3] presented the analysis of connecting rod using analytical and Finite Element Method. They selected a connecting rod used in light commercial vehicle of TATA motors which had recently been launched in the market. They used PRO-E wildfire 4.0 software for modeling of connecting rod and ANSYS 11 software for analysis. ANSYS Workbench module had been used for analysis of connecting rod. In their research, the analytical result was compared to numerical result for all load conditions. It was observed that the minimum stresses for all loading conditions could be found at crank end cap as well as at piston end. K. surdershn Kumar et al [4] presented the modeling and analysis of two wheeler connecting rod. In their study the connecting rod was replaced by aluminum reinforced with boron carbide for Suzuki GS150R motor bike. The structure of connecting rod was modeled using pro/E Wildfire 4. Finite Element Analysis of the connecting rod has been done using ANSYS software. A static analysis was carried out to obtain the von-misses shear stresses and strains for given loading conditions. The results showed that the working factor of safety is nearer to theoretical factor of safety in aluminum boron carbide. The weight of the connecting rod also reduced.

Anil Kumar et al [5], presented an optimization method of connecting rod parameters using CAE tools. They reported on optimized weight and reduced inertia forces on the existing connecting rod, which was obtained by changing design variables in the existing connecting rod design. The model was developed in pro/E Wildfire 5.0 and then imported as a Para solid (xt) from ANSYS Workbench. The stress was found maximum at the piston end and this can be reduced by increasing the material near the piston end. The weight of the connecting rod has also reduced but it was not significant. However, the inertia force has reduced. Vivek et al [6] carried out stress analysis of I.C Engine connecting rod using Finite Element Method. The geometrical model of the connecting rod was modeled using pro/E Wildfire 4.0 and ANSYS Workbench 11.0 software. They concluded from the theoretical and finite element analysis that the stresses induced in the small end of the connecting rod are greater than the stress induced at the big end.

\subsection{Design of Connecting Rod for the Crank-rocker Engine}

Several automotive engineers had attempted to design a crank-rocker engine and some of them patented their work. Based on patent searches, it was discovered that there are a few patented designs which also used the concept of crank rocker engine. For a case study, two crank-rocker engines were considered.

Bowell A. L, has invented certain new and useful improvements in internal combustion engines (Crank-rocker Engine). He accomplished by arranging the diameter of cylinder and the length of the stroke with the reference to an intermediate transmission (rocker lever). His results showed that by changing the pivot position, the cylinder stroke increased and this gave a grater movement of the piston and a consequent improvement in the quality of the combustion [7].

Hunter, patented a crank-rocker opposed piston engine. The production example of these was the 2stroke diesel Commer TS3 engine built by Tilling-Stevens in the Rootes Group [8]. They concluded that the crank-rocker opposed piston engine has minimum bulk and weight, excellent fuel consumption and very lightly loaded crankshaft main bearings. In addition, the engine has other features associated with it, such as minimum maintenance cost and reduces wear problems. The basic configuration of two engines is shown in figure $1 \mathrm{a}$ and $\mathrm{b}$.

It can be noted that the two previous engines have two different designs of connecting rods. The former and the latter made use of the similar designs as shown in figure $2 \mathrm{a}$ and $\mathrm{b}$ respectively. 


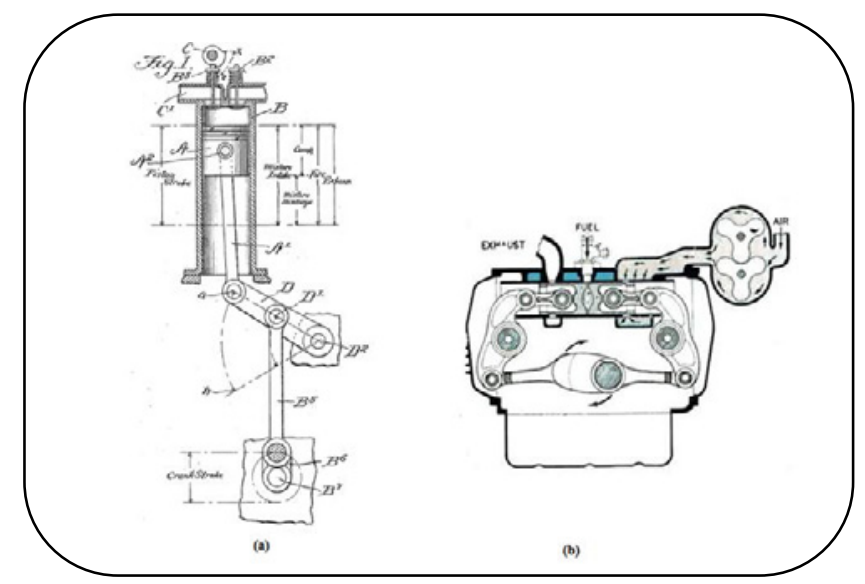

Figure 1. Two types of crank-rocker engine [7-8].

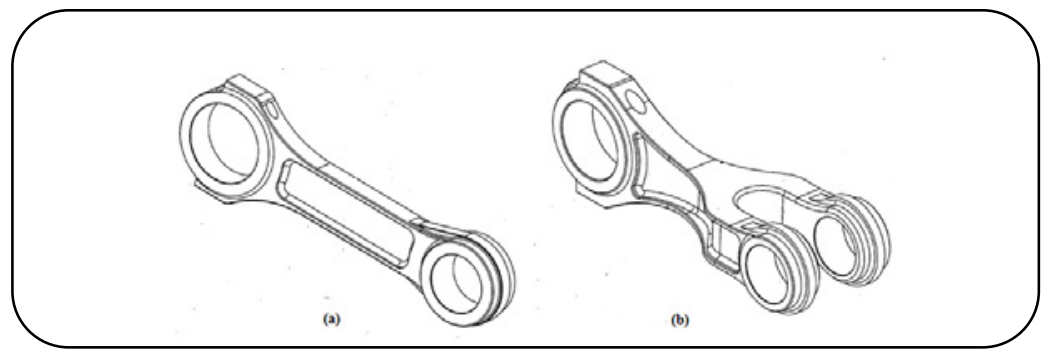

Figure 2. Two types of crank-rocker connecting rod [9].

In general, the function of the connecting rod for crank-rocker engine is to convert oscillating motion from the rocker to the rotary motion of a crankshaft. Due to the differences in thoughts, it is questionable on which design has a better performance. This study was conducted on a crank-rocker engine as previously stated and the connecting rods from similar engines were studied in this research. The main objective is to evaluate and propose a better suitable design for the connecting rod of the crank-rocker engines. In order to achieve this, a comparison study for such design parameters of the existing design was conducted. In this paper, static analysis of two crank-rocker connecting rods have been performed in order to determine the von-misses stress for the given loading conditions using Finite Element Analysis Software ANSYS 14.0. Two cases were studied, firstly, the load was applied at the rocker pin end and fixed at the crank end as a compressive load, and secondly, the load is applied at the rocker pin as a tensile load. For both cases, the axial load was set at 3770N (Gas Fore) in both tension and compression which value was calculated from the combustion force.

\section{Material properties of connecting rod}

The material used for the selected connecting rod used in the simulation is carbon steel and the properties of the material are presented in the Table 1.

Table 1. Material Properties of Connecting rod (Steel)

\begin{tabular}{|c|c|}
\hline Material Selected & Steel \\
\hline Young's Modulus(E) & $2.0 \mathrm{e}+005 \mathrm{Mpa}$ \\
\hline Poisson's Ratio & 0.3 \\
\hline Density & $7.85\left(1000 \mathrm{Kg} / \mathrm{mm}^{\wedge} 3\right)$ \\
\hline Tensile Yield Strength & $250 \mathrm{Mpa}$ \\
\hline Compressive Yield Strength & $250 \mathrm{Mpa}$ \\
\hline
\end{tabular}




\section{3D models of the connecting rods}

The geometrical models of the connecting rods were developed in CATIA v5 software, and two models of connecting rod are shown in figure $3 \mathrm{a}$ and $\mathrm{b}$. The two connecting rods were modeled to have the same volume for apple-to-apple comparisons.

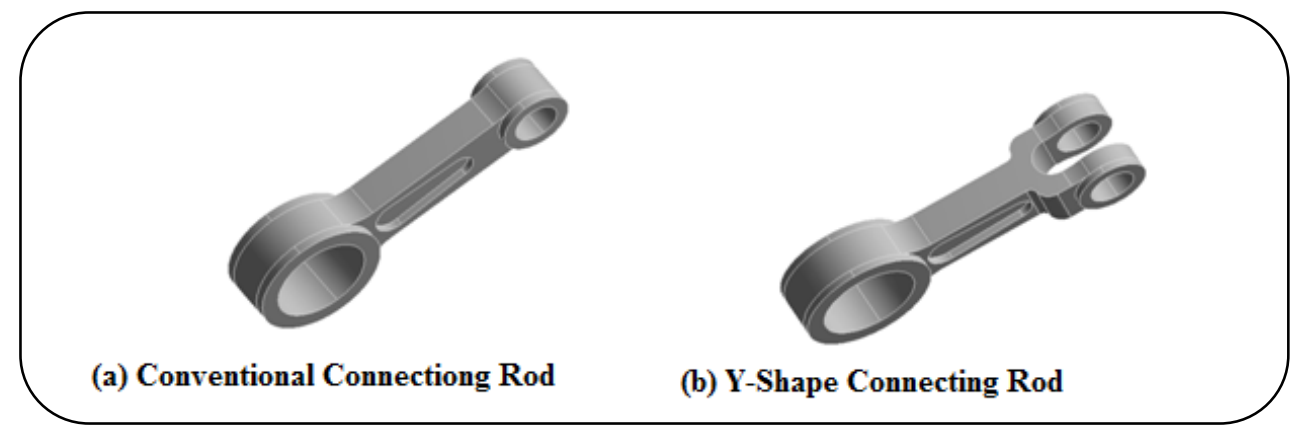

Figure 3. 3D models of connecting rods

\section{FEA result and discussion}

\subsection{Case one (Compressive load)}

The analysis was carried out using CATIA V5 and ANSYS work bench software. The load was applied at the small end of connecting rods as compressive load and the big end side was fixed. The results for the von-misses stress was obtained from the ANSYS Work bench.

From figure 4(a), it is found that the maximum stress of magnitude of $11.5 \mathrm{Mpa}$ is concentrated at the end of the shank of connecting rod near to the crank end, while the minimum stress occurs at the crank end with the value of $3.5 \mathrm{e}-4 \mathrm{Mpa}$. It is observed from figure 4(b), the maximum and minimum stress occurs at the small and big ends for $\mathrm{y}$-shape connecting rod with the magnitudes of 48.8Mpa and 3.2e-4Mpa respectively.

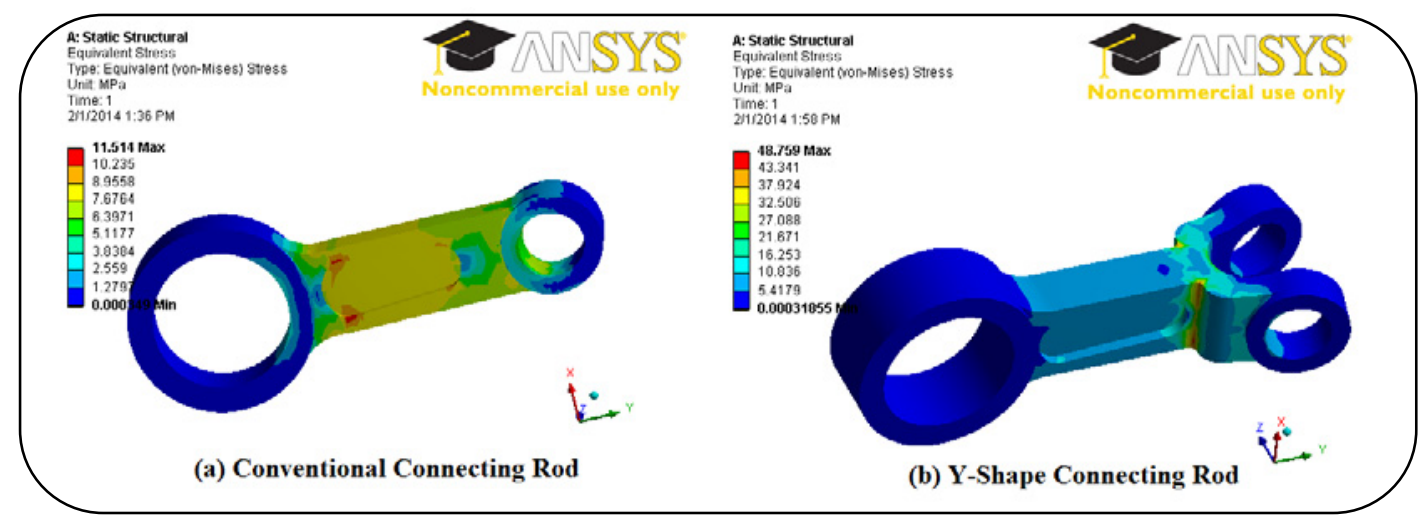

Figure 4. Von-misses stress of the two types of the connecting rods at compressive load of $3770 \mathrm{~N}$.

\subsection{Case two (Tensil load)}

From figure 5(a) the maximum stress occurs at the rocker pin end of the connecting rod with value of $41.0 \mathrm{Mpa}$ and minimum stress occurs at the crank end of the connecting rod with value of $3.5 \mathrm{e}-4 \mathrm{Mpa}$. 
Figure 5(b) shows similar trend of stress distribution with the maximum and minimum of $49.1 \mathrm{Mpa}$ and 3.2e-4Mpa respectively.

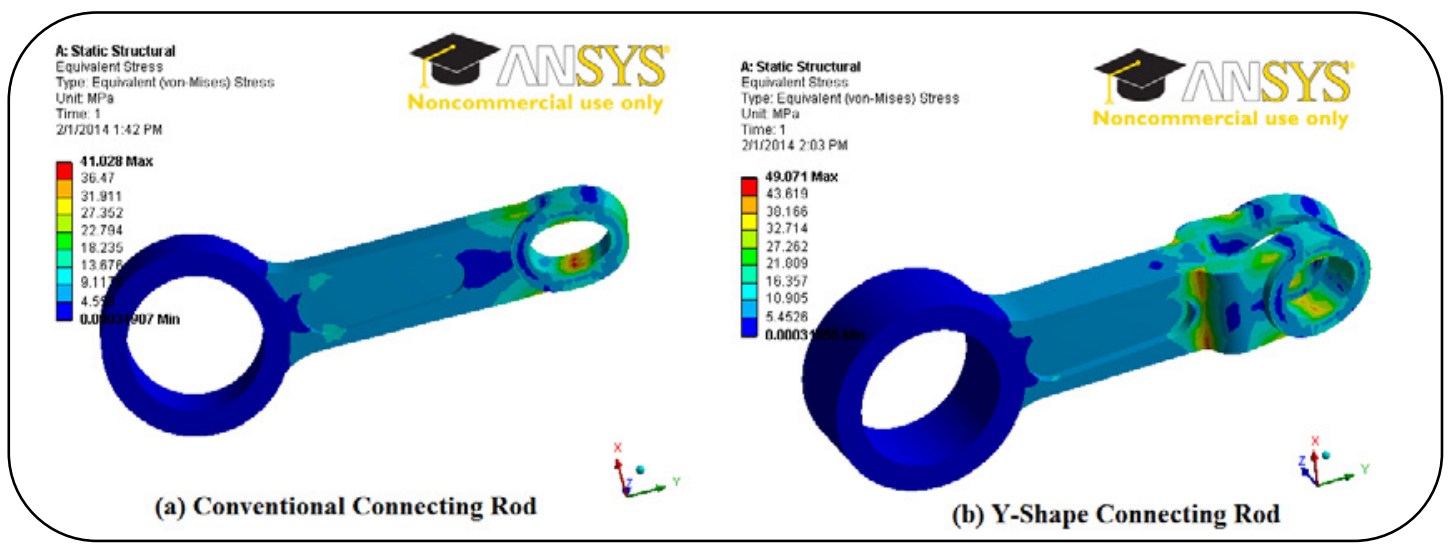

Figure 5. Von-misses stress of the two types of the connecting rods at tensil load of $3770 \mathrm{~N}$.

\section{Conclusion}

In this paper, two models of connecting rod for a crank-rocker engine have been modeled in CATIA V5, and the Finite Element Analysis of the two models have been conducted using FEA tool (ANSYS Workbench). The results from static analysis and the induced Von-misses stress have shown that the conventional connecting rod has yielded less stress for both cases of compression and tension than the y-shape connection rod model for the same weight design. An optimization can be done by redesigning with better parameters (i.e. chamfers, different materials, etc.) in order to reduce the stress. Based on these results, it can be concluded that the conventional connecting rod is better to be used for the crank-rocker engine.

\section{References}

1. Visser D. A comparision of Manufactoring Technologies in the Connecting Rod Industry,Submisssion to FIERF (2008).

2. B. Anusha, C.Vijaya Bhaskar Reddy. Modeling and Analysis of Two Wheeler Connecting Rod by Using Ansys. JMCE.6( 5), 83-87 (2013).

3. Prof. N.P. Doshi, Prof .N.K. Ingole. Analysis of Connecting Rod Using Analytical and Finite Element Method. IJMER. 3( 1), 65-68 (2013).

4. K. Sudershn Kumar, Dr. K. Tirupathi Reddy, Syed Altaf Hussain. Modeling and Analysis of Two Wheeler Connecting Rod. IJMER. 2(5), 3367-3371 ( 2012).

5. Anil kumar, Kamaldeep Grover, Balvinder Budania. Optimization of Connecting Rod Parameters using CAE Tools. IJLTET. 1 (3),(2012).

6. Vivek. C. Pathade, Bhumeshwar Patle, Ajay N. Ingale. Stress Analysis of I.C Engine Connecting Rod by FEM. IJEIT.1(3), 2277-3754 (2012).

7. Powell, A. L. Internal Combustion Engine. U.S. Patent 1567172. (1925).

8. J.P. Pirault, and M. Flint.Opposed Piston Engines: Evolution, Use, and Future Applications. SAE International, Warrendale, PA (2009).

9. James U. Lemke et al.Single-crankshaft, opposed-piston engine constructions. U.S. Patent 20110186017. (2011). 